\title{
ISONOMIA ENTRE HOMENS E MULHERES NO RECEBIMENTO DE PENSÃO POR MORTE DE CÔNJUGE SERVIDORA PÚBLICA: ANÁLISE COMPARATIVA NO CONTEXTO ALEMÃO E BRASILEIRO
}

\section{Renata Duval Martins*}

\section{RESUMO:}

O presente trabalho tem por escopo realizar análise comparativa de decisão proferida, em 1975, pelo Tribunal Constitucional Federal da Alemanha e de decisão proferida, em 2007, pelo Supremo Tribunal Federal do Brasil, ambas versando sobre a violação do princípio da isonomia entre homens e mulheres na aferição do benefício previdenciário de pensão por morte de servidor público. Observam-se discrepâncias entre os regramentos que embasaram a não concessão do benefício pela Administração Pública. No entanto, verifica-se a similaridade da qual decorreu a revogação das normas que embasaram a denegação dos benefícios administrativamente, ou seja, a violação constitucional do princípio da isonomia.

PALAVRAS-CHAVES: Alemanha; Brasil; Pensão por morte; Servidor Público; Isonomia.

\section{GENDER EQUALITY IN RECEIVING DEATH PENSION OF A CIVIL SERVANT: COMPARATIVE ANALYSIS IN THE GERMAN AND BRAZILIAN CONTEXT}

\begin{abstract}
This paper performs a comparative analysis of a ruling made in 1975 by the Federal Constitutional Court of Germany and a ruling made in 2007 by the Supreme Federal Court of Brazil, both dealing with the violation of the principle of equality among men and women in receiving death pension of a civil servant. Discrepancies are observed between the rules that supported the non-granting of the benefit by the Administration. However, there is a similarity which resulted in the repeal of the norms that led to the denial of benefits administratively, that is, the violation of the principle of equality.
\end{abstract}

KEYWORDS: Germany; Brazil; Death pension; Public server; Isonomy.

\section{INTRODUÇÃO}

O presente artigo visa comparar decisão do Tribunal Constitucional Federal da Alemanha e decisão do Supremo Tribunal Federal do Brasil que se assemelham tendo em vista os seguintes fatores: ambas as decisões se referem ao pedido de pensão por morte de servidora pública; os beneficiários são viúvos; foi-lhes negado o benefício em âmbito

\footnotetext{
* Doutoranda em Direito pela Universidade Federal do Rio Grande do Sul. Mestra em Direito pela Universidade Federal do Rio Grande do Sul. Bacharela em Direito pela Universidade Federal do Rio Grande. Assistente em Administração na Universidade Federal do Rio Grande. Advogada. Endereço postal: Rua Padre Feijó, nº 283, Rio Grande/RS, CEP 96.211-520. Endereço eletrônico: renata_duval@hotmail.com e renata.duval.martins@gmail.com.
} 
administrativo com base em legislações estaduais que feriam o princípio da isonomia, constitucionalmente previsto; nos dois casos era necessário ao marido demonstrar dependência econômica para usufruir da prestação, porém, no caso brasileiro o critério era ainda mais restritivo, pois a dependência econômica só poderia ser decorrente de invalidez.

No primeiro item do trabalho são esmiuçadas as decisões judiciais. No primeiro subitem se analisa a decisão do Tribunal Constitucional Federal da Alemanha e no segundo subitem se aborda a decisão do Supremo Tribunal Federal. Em ambos os casos verifica-se a violação do princípio da isonomia nas concessões de pensão por morte de servidora pública, tendo em vista que a norma tratava o viúvo de uma servidora civil pior do que a viúva de um servidor civil. Além disso, demonstra-se falta de igualdade entre servidora pública e servidor público, pois as servidoras apesar de cumprirem as mesmas condições, exercerem as mesmas funções e assumirem as mesmas responsabilidades que os servidores do sexo masculino em igual cargo/função, não eram amparadas pela mesma proteção e garantias do serviço com relação à manutenção da família após o falecimento.

Avançando-se ao item dois do artigo, faz-se uma análise comparativa dos casos com base no princípio da isonomia e as características do benefício de pensão por morte, especificamente, dos servidores públicos. Analisam-se, assim, as normas constitucionais alemãs e brasileiras aplicáveis aos casos, bem como se traz os conceitos doutrinários do princípio e instituto abordados. Tal objetivando demonstrar a intrínseca relação entre os casos, bem como entre as soluções adotadas pelos Tribunais das duas nações.

Cabe ressaltar que não é objeto deste trabalho a análise dos valores do benefício de pensão por morte, tampouco como é dividido o valor entre os dependentes, nem mesmo qual é o rol de dependentes. Ademais, não serão analisados os regramentos aplicáveis atualmente nos dois países para a concessão de pensão por morte. O presente trabalho visa apenas analisar as normas existentes no recorte de tempo dos fatos expostos e das decisões emitidas. Feitas as considerações introdutórias, segue-se para o início da análise, abordando os aspectos gerais dos casos.

\section{ASPECTOS GERAIS DOS CASOS DE PENSÃO POR MORTE DE SERVIDORA PÚBLICA}

1.1 Caso julgado pelo Tribunal Constitucional Federal da Alemanha - BVERFGE 39, 196 
O caso BVERFGE 39, 196 do Tribunal Constitucional Federal Alemão foi julgado pelo Segundo Senado, em 12 de março de 1975 e corresponde ao controle concreto de constitucionalidade. Neste episódio, uma servidora pública morreu em um acidente, em 1964, e seu viúvo teve o pedido de recebimento de pensão por morte da esposa negado pela Administração.

Tal ocorreu com base em um dispositivo legal, o $§ 141$ da Lei do Funcionalismo Público (Beamtengesetz) do Estado de Renânia do Norte, em Vestfália. O supracitado dispositivo já estava revogado à época da Reclamação Constitucional, no entanto, o exame de constitucionalidade era relevante a fim de conceder o recebimento retroativo da pensão e para o julgamento de uma ação de perdas e danos.

Os fatos que deram origem à lide tiveram início com o viúvo (demandante) exigindo pensão por morte de sua esposa com fulcro no $§ 141$ da Lei dos Servidores Públicos para o Estado de Renânia do Norte, em Vestfália, na versão da lei de $1^{\circ}$ de junho de 1962 . Este pedido foi rejeitado pela Administração, pois o viúvo por ser do sexo masculino precisaria comprovar o direito de receber alimentos da falecida, não sendo suficiente seu estado civil de casado quando da ocorrência da morte de seu cônjuge.

Segundo a versão de 1962 da norma, o direito da viúva de receber a pensão por morte de cônjuge funcionário público era presumida, enquanto o direito (necessidade) do viúvo ao recebimento de pensão por morte de cônjuge servidora pública precisava ser comprovado, tal ocorrendo apenas nos casos em que existisse um dever de manutenção legal, por exemplo, quando estando o casal divorciado, o homem estivesse recebendo alimentos da ex-esposa e tendo sido esta a responsável principal pelo insucesso da relação.

Em setembro de 1966, o viúvo ingressou com uma ação no Tribunal Administrativo de Münster requerendo a pensão por morte, mas seu pedido restou indeferido em primeira instância. Houve apelação e o processo foi encerrado, pois o $§ 141$ da Lei dos Servidores Públicos para o Estado de Renânia do Norte foi modificado, bem como, em realidade, o viúvo passou a receber o benefício de pensão por morte com fulcro na referida norma a partir de $1^{\circ}$ de setembro de 1966, mesmo mês no qual intentou a ação. Assim, foi-lhe negado apenas o pedido de recebimento retroativo, relativo ao período correspondente à data do acidente no qual sua esposa faleceu e a data de início da ação. 
A seguir, o viúvo processou o advogado que o havia representado no processo administrativo, alegando que esse lhe causou dano culposamente, tendo em vista que no processo movido não pode ser apreciada pelo Tribunal Constitucional Federal a inconstitucionalidade do dispositivo do $§ 141$ da Lei dos Servidores Públicos para o Estado de Renânia do Norte, na versão da lei de $1^{\circ}$ de junho de 1962, resultando tal impossibilidade no não pagamento da pensão por morte relativa ao período de 1964 a setembro de 1966.

O Tribunal Estadual de Renânia do Norte acreditando na inconstitucionalidade do § 141 na versão de $1^{\text {o }}$ de junho de 1962 (versão revogada) da Lei do Funcionalismo Público em face do artigo 3, parágrafos 2 e 3 da Lei Fundamental, e tendo em vista que a validade do julgamento da ação dependia disto, suspendeu o processo de compensação até o Tribunal Constitucional Federal determinar a constitucionalidade ou inconstitucionalidade do dispositivo em questão. Tal análise era necessária, pois se a versão revogada fosse considerada constitucional o processo no Tribunal Distrital deveria ser descartado, enquanto se a versão revogada fosse de fato uma norma inconstitucional e, portanto, nula, por estabelecer ao viúvo de servidora pública condições para percepção de pensão por morte piores, mais restritivas, do que aquelas impostas às viúvas de servidores públicos, o processo no Tribunal Distrital deveria prosseguir.

O Tribunal Constitucional Federal admitiu a Representação do Tribunal Estadual e declarou o antigo $§ 141$ como nulo, pois impunha ao viúvo de servidora pública para receber a pensão por morte desta critério não imposto à viúva de servidor público. Logo, diferenciando viúvos de viúvas, criava uma desvantagem para o primeiro grupo em relação ao segundo e, não tendo tal diferenciação justificação constitucional, verificou-se que esta era inconstitucional. Desta forma, a disposição normativa foi considerada nula pelas mesmas razões que disposição similar na Lei dos Servidores Públicos de Hamburgo fora anulada pela corte no dia 11 de abril de 1967 (BVerfGE 21, 329).

O demandado argumentou que o demandante só poderia se beneficiar da anulação a contar do dia $1^{\circ}$ de abril de 1967 , data na qual o $§ 141$ da Lei dos Servidores Públicos para o Estado de Renânia do Norte foi emendado, não podendo lhe cobrar pelo período anterior, de 1964 a setembro de 1966. A Corte considerou ser aparente a culpa do advogado/demandado quanto a não ter requerido a pensão por morte para seu cliente relativa ao período anterior supracitado, no entanto, também considerou a possibilidade da culpa ser do Ministro das Finanças do Estado de Renânia do Norte, pois este em 18 de outubro de 1967 sabia ou tinha 
que saber da situação e era seu dever fazer o necessário a fim de pagar para o viúvo os valores relativos à pensão do período anterior à entrada em vigor das mudanças no $\S 141$. Apesar do exposto, a Corte ressaltou não ser seu papel decidir ou analisar as questões acima expostas, mas apenas a constitucionalidade do $§ 141$.

Sendo assim, a Corte chegou as seguintes conclusões: $1^{\circ}$ ) o $\S 141$ conforme sua redação em 1962 era inconstitucional; $2^{\circ}$ ) segue-se no presente caso a mesma opinião legal de decisão anterior sobre a Lei dos Servidores Públicos de Hamburgo; $3^{\circ}$ ) o $§ 141$ tratava o viúvo de uma servidora civil pior do que a viúva de um servidor civil, bem como o restante dos dependentes do viúvo em contraste com os dependentes da viúva, tendo em vista que impunha ao viúvo comprovar a existência de um dever legal de manutenção por parte da servidora a fim de poder receber a pensão por morte desta; $4^{\circ}$ ) essa desigualdade mostra que a legislação claramente viola o princípio da isonomia, em discrepância com o constante no artigo 33 (5) da Lei Fundamental, nesta consta "Artigo 33 [Igualdade de direitos cívicos dos alemães - Serviço público] (5) O estatuto legal do serviço público deve ser regulamentado e desenvolvido de acordo com os princípios tradicionais do funcionalismo público de carreira.", sendo a isonomia um destes princípios tradicionais a serem observados na regulação da prestação dos serviços civis; $5^{\circ}$ ) a remuneração do servidor e de sua família tem a sua raiz comum no serviço público e deve sempre ser considerada no sentido de manutenção de condições apropriadas de sustento, tendo em vista que o servidor público, em princípio, entrega toda a sua força de trabalho para o empregador, mantendo-se disponível a ele por toda sua vida, em troca o empregador tem o dever de prover ao servidor público e à sua família com adequada subsistência na forma de remuneração, por idade avançada e pensão. Tem-se que os salários, as aposentadorias e as pensões são os pré-requisitos para os servidores civis se devotarem ao serviço público como uma profissão por toda a vida, assegurando, assim, estabilidade, bem como confiabilidade ao cumprir o dever designado ao serviço público pela Lei Fundamental; $6^{\circ}$ ) a própria lei prevê o pagamento de pensão do servidor público calculada conforme a última remuneração auferida em serviço; $7^{\circ}$ ) o salário e os benefícios são incorporados como direitos de manutenção indispensáveis, sendo a pensão por morte uma expectativa indispensável garantindo o bem-estar econômico dos parentes do falecido; $8^{\circ}$ ) em respeito à devoção e ao cumprimento leal de seus deveres demonstrados pelo servidor público durante o seu serviço, é dever do Estado prover os membros familiares do servidor público falecido; $9^{\circ}$ ) a lei determina que os órfãos e a viúva/o viúvo de servidor público/servidora 
pública falecido podem ter renda própria, podendo esta inclusive ser superior à pensão; $10^{\circ}$ ) o valor da pensão só é limitado se um certo montante da renda total familiar for alcançado (seja a renda própria dos familiares proveniente de fundos públicos ou não), logo, o Estado deve pagar a pensão por morte do servidor público independentemente de saber se os agregados familiares sofreram ou não uma perda financeira grave em decorrência do falecimento; $11^{\circ}$ ) as servidoras públicas tem que cumprir as mesmas condições, exercer as mesmas funções soberanas e assumir as mesmas responsabilidades que os servidores públicos do sexo masculino em igual cargo/função, logo, ambos estão sujeitos aos mesmo princípios éticos profissionais e amparados pela mesma proteção e garantias do serviço civil e manutenção da família; $12^{\circ}$ ) a manutenção do trabalhador e de sua família está inseparavelmente ligada ao seu salário e emprego, logo, após a morte da servidora pública, a remuneração recebida durante a ativa continua sendo essencial para a alimentação de seus familiares, injustificável não prover tal cobertura aos viúvos; $13^{\circ}$ ) nos termos do artigo 3 , número 2 e 3 da Lei Fundamental, tanto o servidor público quanto a servidora pública devem ser tratados em relação aos cuidados aos membros de sua família imediata de forma igual, ou seja, tanto o viúvo quanto a viúva do servidor público têm que receber o apoio adequado do empregador, não podendo o $§ 141$ da Lei dos Servidores Públicos para o Estado de Renânia do Norte desfavorecer o viúvo, logo, tal norma é nula.

Finalizando a exposição do caso, salienta-se que os artigos da Lei Fundamental da Alemanha utilizados para embasar o posicionamento da Corte foram o artigo 3 sobre Igualdade perante a lei e o artigo 33 sobre Igualdade de direitos cívicos dos alemães - Serviço público ${ }^{1}$. Também, destaca-se que a decisão em face da admissibilidade da Apresentação Judicial foi prolatada por 7 votos a 1, quanto ao restante foi unânime. Assim, restou configurada a inconstitucionalidade do artigo que diferenciava os viúvos de servidoras

\footnotetext{
${ }^{1}$ Artigo 3 [Igualdade perante a lei]

(1) Todas as pessoas são iguais perante a lei. (2) Homens e mulheres têm direitos iguais. O Estado promoverá a realização efetiva da igualdade de direitos das mulheres e dos homens e empenhar-se-á pela eliminação de desvantagens existentes. (3) Ninguém poderá ser prejudicado ou favorecido por causa do seu sexo, da sua descendência, da sua raça, do seu idioma, da sua pátria e origem, da sua crença ou das suas convicções religiosas ou políticas. Ninguém poderá ser prejudicado por causa da sua deficiência.

Artigo 33 [Igualdade de direitos cívicos dos alemães - Serviço público]

(1) Todos os alemães têm, em qualquer Estado, os mesmos direitos e deveres cívicos. (2) Todos os alemães têm igual acesso a qualquer cargo público, de acordo com sua aptidão, capacidade e desempenho profissional. [...] (4) O exercício de funções de soberania será confiado, como regra geral de caráter permanente, a funcionários públicos, sujeitos a relações de serviço e de fidelidade ancoradas no direito público. (5) O estatuto legal do serviço público deve ser regulamentado e desenvolvido de acordo com os princípios tradicionais do funcionalismo público de carreira.
} 
públicas das viúvas de servidores públicos quanto ao direito à pensão por morte, pois tal resultava em clara violação ao princípio da isonomia. Desta forma, segue-se para o subitem seguinte do presente estudo com o resumo de processo judicial similar transcorrido no Brasil.

\subsection{Caso julgado pelo Supremo Tribunal Federal do Brasil - RE 385397 AgR/MG}

Em 29 de junho de 2007, por unanimidade, o Tribunal Pleno do Supremo Tribunal Federal julgou o Agravo Regimental no Recurso Extraordinário no 385.397-0 de Minas Gerais, o relator do caso foi o Ministro Sepúlveda Pertence, constaram como agravante o senhor Antonio de Oliveira Rosa e como agravado o Instituto de Previdência dos Servidores do Estado de Minas Gerais (IPSEMG). O agravo regimental foi provido, para conhecer do recurso extraordinário e negar-lhe provimento, tendo em vista a ausência de prequestionamento do artigo $5^{\circ}, \mathrm{XXXVI}^{2}$, da Constituição Federal, tido por violado, incidindo no presente caso as Súmulas 282 e 356 do Supremo ${ }^{3}$.

Observa-se no caso ora estudado que o viúvo solicitou a pensão por morte de servidora pública estadual, ocorrida antes da Emenda Constitucional 20/98, afirmando que a lei estadual mineira, violando o princípio da igualdade do artigo $5^{\circ}$, I, da Constituição Federal, exigia do marido, para que recebesse a pensão por morte da mulher, o requisito da invalidez, não sendo este exigido em relação à viúva. Assim, dizia o solicitante, evidenciava-se que o dado sociológico que se presumia em favor da mulher era o da dependência econômica e não, o de invalidez, razão pela qual também não podia este ser exigido do marido. Também, salientou-se que da condição de invalidez decorria a dependência econômica, porém a condição de dependência econômica não implicava em declaração de invalidez.

Tem-se que, em 28 de outubro de 2003, a Primeira Turma do STF deu provimento a recurso extraordinário oposto a acórdão do Tribunal de Justiça do Estado de Minas Gerais que concedeu a extensão de pensão por morte ao viúvo de servidora pública. O recorrente, ou seja,

\footnotetext{
${ }^{2}$ Art. $5^{\circ}$

XXXVI - a lei não prejudicará o direito adquirido, o ato jurídico perfeito e a coisa julgada;

${ }^{3}$ Súmula 282

É inadmissível o recurso extraordinário, quando não ventilada, na decisão recorrida, a questão federal suscitada. Súmula 356

O ponto omisso da decisão, sobre o qual não foram opostos embargos declaratórios, não pode ser objeto de recurso extraordinário, por faltar o requisito do prequestionamento.
} 
o Instituto de Previdência dos Servidores do Estado de Minas Gerais (IPSEMG) apontou que houve violação aos artigos $5^{\circ}$, I e XXXVI, 195, § $5^{\circ}$ e 201, V, da Constituição Federal.

Tal decisão teve a seguinte justificativa: ocorre que o texto anterior à Emenda Constitucional 20/98 apenas definia a correspondência entre o valor da pensão e a totalidade dos vencimentos ou proventos do servidor falecido, sem qualquer referência a outras questões, como, por exemplo, os possíveis beneficiários da pensão por morte. Além disso, a redação do artigo 40 da Constituição Federal antes da Emenda não fazia remissão ao regime geral da previdência social, logo, era impossível a invocação no presente caso do texto do artigo $195, \S 5^{\circ}$ - exigência de fonte de custeio para a instituição de benefício -, bem como do art. 201, V, ambos da Constituição Federal — inclusão automática do cônjuge, seja homem ou mulher, como beneficiário de pensão por morte.

Ademais, o Supremo Tribunal Federal já havia decidido que, a partir do julgamento do RE 204.193 (Velloso, DJ 31.10.02), afastava-se a inclusão automática do viúvo como beneficiário da pensão por morte de sua esposa, quando não houvesse previsão legal de custeio do referido benefício. Neste julgamento, acentuou-se que, no Brasil, o homem era apontado como o provedor da família, logo, existiria presunção de dependência da esposa, sendo este dado sociológico considerado na elaboração legislativa. Portanto, para que o marido fosse presumido dependente da esposa era preciso lei específica dispondo a respeito, porque o dado sociológico acima indicado sempre fora considerado no custeio do benefício, devendo-se respeitar a norma inscrita no art. 195, § 5º da Constituição Federal.

Assim, tendo em vista que a legislação do estado de Minas Gerais que regulamentava os benefícios à época do óbito da esposa do recorrido (Lei 9.380/86) previa a inclusão do marido como dependente da segurada somente no caso de invalidez (art. $7^{\circ}, \mathrm{I}$ ), este não poderia receber a pensão, pois não havia comprovado a dependência econômica, bem como ausente a fonte de custeio para o pagamento (art. 195, § 5º da Constituição), sendo necessária lei específica.

Por fim, o Supremo ressaltou que a Lei 13.455/00 que incluiu o marido como dependente dos segurados do Instituto de Previdência dos Servidores do Estado de Minas Gerais (IPSEMG), bem como criou a fonte de custeio necessária, entrou em vigor somente após a morte da esposa do recorrido, não podendo, portanto, retroagir para beneficiá-lo, por ser caso regido pela legislação anterior. 
Como já exposto, o recurso extraordinário foi provido, porém o recorrido ingressou com o agravo regimental. O agravante alegou que o acórdão do Tribunal de Justiça do Estado de Minas Gerais não contrariou o artigo 195, § 5º da Constituição Federal, bem como que não era necessária a previsão legal de fonte de custeio para a implementação do benefício de pensão por morte, sendo autoaplicável o art. 201, V, da Constituição Federal.

O relator expôs que o agravante não tinha razão, pois a inexistência de lei específica criando fonte de custeio para o implemento de pensão por morte para o cônjuge do sexo masculino inviabilizava o benefício. Além disso, a lei estadual vigente à época do falecimento da segurada previa que somente o marido inválido era considerado dependente. Logo, o acórdão contrariou o art. $195, \S 5^{\circ}$, da Constituição Federal, porque estendeu benefício a quem não estava incluído no cálculo das contribuições. Assim, justificou o relator a negativa ao provimento ao agravo regimental no recurso extraordinário. A seguir pediu vista dos autos o Ministro Marco Aurélio.

Em 02/12/2003, na Primeira Turma, o Ministro Marco Aurélio contrariando o decidido pelo relator, conheceu do agravo e lhe deu provimento, bem como assentou que o recurso extraordinário interposto pelo Instituto de Previdência dos Servidores do Minas Gerais não tinha condições de ser conhecido. Justificou o voto no agravo interposto pela impropriedade do óbice vislumbrado, pois seria dispensável a fonte de custeio para implementar o benefício inserto na própria Constituição Federal.

O Ministro Marco Aurélio ressaltou que o Juízo e o Órgão Revisor - este, no julgamento da apelação - reafirmaram o direito do viúvo a receber a pensão em virtude da morte da servidora pública, frisando a alteração da legislação local pretérita, que excluía o benefício, tendo em conta a própria Constituição Federal na qual consta que "homens e mulheres são iguais em direitos e obrigações". Tampouco esta diferencia homens e mulheres no tocante ao benefício de pensão por morte, conforme se verifica no artigo 201, V. Também, salientou a existência de fonte de custeio, pois a contribuição devida pelo servidor, homem ou mulher, cobre a pensão, pouco importando o dependente que dela venha a usufruir. Logo, estando a servidora falecida integrada ao sistema de previdência social, verificava-se que esta contribuiu para assegurar a pensão aos dependentes.

Continuando, o Ministro expôs que a regra do artigo 195, § $5^{\circ}$, da Constituição Federal, ao determinar que "Nenhum benefício ou serviço de seguridade social poderá ser criado, majorado ou estendido sem a correspondente fonte de custeio total", referia-se à 
atividade legiferante posterior na criação de outras espécies de benefícios, tal não restringia os benefícios previstos na própria Constituição Federal. Neste ponto, ressaltou-se que a pensão por morte é benefício constitucional, criado indistintamente para cônjuge ou companheiro do sexo masculino ou feminino, com fonte de custeio. Logo, pelas razões expostas o Tribunal ao julgar a apelação entendeu pela auto aplicabilidade do preceito assegurador de pensão integral, afastando a condição de uma fonte de custeio, pois esta já existia.

Após o voto do Ministro Marco Aurélio, dando provimento ao agravo regimental, a Turma decidiu remeter o agravo a julgamento do Tribunal Pleno, ocorrendo este em 29 de junho de 2007. Do julgamento pelo Plenário, o Supremo, por unanimidade e nos termos do voto do Relator, deu provimento ao agravo para conhecer do recurso extraordinário e negarlhe provimento.

O relator, o Ministro Sepúlveda Pertence, iniciou seu voto manifestando que o voto do Ministro Marco Aurélio, em 02 de março de 2003, convenceu-lhe que a questão ora analisada merecia maiores considerações. Assim, o relator expôs que exigência de fonte de custeio para que o cônjuge do sexo masculino usufruísse da pensão por morte de sua mulher e a necessidade de lei específica para a sua inclusão como dependente da esposa, nos termos do que ficou estabelecido no julgamento do RE 204.193, até então usado pelo relator como guia para a análise na presente ação, conflitava com a jurisprudência do Supremo firmada no sentido da aplicabilidade imediata e independente de fonte de custeio dos benefícios previstos pela própria Constituição Federal.

Porém, salientou a peculiaridade do caso, pois a servidora, esposa do recorrente, faleceu no dia 26 de dezembro de 1997, ou seja, antes da promulgação da Emenda Constitucional 20/2018, época na qual não havia o $§ 12$ do artigo 40 da Constituição Federal: “Além do disposto neste artigo, o regime de previdência dos servidores públicos titulares de cargo efetivo observará, no que couber, os requisitos e critérios fixados para o regime geral de previdência social." Logo, não seria possível se invocar os artigos 195 , §5 e 201, V, da Constituição Federal no caso ora sob análise, devendo-se levar em consideração apenas a redação do artigo 40 antes da Emenda Constitucional 20/98, sem remissão ao regime geral da previdência social, uma vez que aquela era a disposição constitucional em vigor na data do falecimento da servidora.

No texto anterior à Emenda Constitucional 20/98, o objetivo dos dispositivos era apenas definir a correspondência entre o valor da pensão e a totalidade dos vencimentos ou 
proventos do servidor falecido, sem qualquer referência a outras questões, como, por exemplo, os possíveis beneficiários da pensão por morte. Analisando-se a questão por este viés e tendo em vista o princípio de direito intertemporal, segundo o qual se regula o direito à pensão pela norma vigente à época do Óbito, o direito à pensão estaria restrito ao marido inválido, hipótese que não é a vertente.

No entanto, confrontando-se a exigência de invalidez do marido para ser beneficiário de pensão por morte da esposa com o princípio da isonomia do art. $5^{\circ}$, I, da Constituição Federal, verificava-se que não se tratava de estender ao cônjuge do sexo masculino a presunção de dependência que favorece à mulher, mas de não impor ao viúvo um requisito que não era imposto à viúva a fim de gozar do direito à pensão, ou seja, o requisito da invalidez.

Neste ponto de sua argumentação o Ministro citou uma análise comparativa com a Justiça Alemã feita pelo Ministro Gilmar Mendes, abordando nesta comparação inclusive o caso objeto de estudo no subitem anterior do presente artigo. Observou-se que a legislação examinada pelo Tribunal Constitucional Alemão tinha disciplina diversa da lei previdenciária do Estado de Minas Gerais, pois este exigia mais que a condição de dependência econômica ao cônjuge do sexo masculino que pleiteava o benefício de pensão por morte. Enquanto o caso alemão tratou da extensão ao viúvo da presunção de dependência que favorece à viúva, o caso brasileiro tratou de não impor ao viúvo a exigência de invalidez (da qual decorria a dependência econômica) para fins de recebimento do benefício previdenciário.

Por fim, em seu voto o relator afastou a afronta ao art. $5^{\circ}$, XXXVI, da Constituição Federal, ante a ausência de prequestionamento, nos termos das Súmulas 282 e 356 do STF, bem como deu provimento ao agravo para conhecer do recurso extraordinário e negar-lhe provimento por afrontar o princípio da isonomia tendo em vista a exigência de invalidez do viúvo. Logo, o Ministro relator modificou o voto esposado anteriormente na Turma, seguindo agora no Pleno a conclusão do Ministro Marco Aurélio, porém por fundamentação diversa, ou seja, para o relator o $§ 12$ do artigo 40 da Constituição Federal não devia ser aplicado ao caso, porque o óbito era anterior à Emenda Constitucional que o acresceu ao texto, mas era inconstitucional a exigência da lei estadual mineira por violar o princípio da isonomia entre viúvos e viúvas para concessão de pensão por morte de servidor público.

Encerrado o primeiro ponto do estudo, dividido em dois subitens, segue-se para a análise comparativa dos casos descritos, discorrendo sobre os dois pontos principais de 
semelhança entre estes, ou seja, a violação do princípio da isonomia e a ocorrência de tal no pedido de concessão de pensão por morte, impondo ao viúvo de servidora pública critério mais restritivo do que o imposto à viúva de servidor público.

\section{ANÁLISE COMPARATIVA NOS CONTEXTOS ALEMÃO E BRASILEIRO}

\subsection{Princípio da isonomia}

O princípio da isonomia ou igualdade é apresentado em termos gerais na Lei Maior do Brasil e na Lei Fundamental da Alemanha, bem como em normas específicas relacionadas a gênero, tentando mitigar diferenciações injustificáveis e maléficas entre homens e mulheres. Inicialmente, cabe perguntar: em que consiste o princípio da isonomia? Qual o seu conceito?

Em um conceito enxuto, pode-se dizer que o princípio da isonomia é aquele que oferece equiparação entre as partes, homogeneizando as relações e protegendo os que se encontram em situação de vulnerabilidade em um contexto específico. Logo, o princípio não existe para proteger sempre um mesmo grupo frente a outro, por exemplo, proteger sempre as mulheres frente aos homens, os negros frente aos brancos etc.

A isonomia não tem ideologias, bandeiras ou partidos para defender, a sua base é a defesa daquele - quem quer que seja - que está em situação de vulnerabilidade, igualando os desiguais e coibindo vantagens ou desvantagens injustificáveis. Assim, verifica-se que são possíveis ocorrências nas quais os homens estejam em situação de vulnerabilidade, sendo prejudicados em ofensa ao princípio da isonomia, conforme os casos estudados no item 1 do presente trabalho.

O princípio da isonomia é para todos que dele precisem, não escolhe grupos. E se aparentemente resguarda mais algumas categorias do que outras, tal se deve ao fato de alguns grupos necessitarem se socorrer no princípio com maior frequência, tendo em vista questões históricas, culturais e sociais. Rui Barbosa citado por Maria Christina Barreiros D’Oliveira traz o seguinte conceito de isonomia:

Ruy Barbosa baseando-se na lição Aristotélica proclamou que "a regra da igualdade não consiste senão em tratar desigualmente os desiguais na medida em que se desigualam. Nesta desigualdade social, proporcional e desigualdade natural, é que se acha a verdadeira lei da igualdade. Os mais 
são desvarios da inveja, do orgulho ou da loucura. Tratar com desigualdade os iguais, ou os desiguais com igualdade, seria desigualdade flagrante, $e$ não igualdade real. Os apetites humanos conceberam inverter a norma universal da criação, pretendendo, não dar a cada um, na razão do que vale, mas atribuir os mesmos a todos, como se todos se equivalessem”. (D'OLIVEIRA, 2011, p. 3).

A diferenciação entre igualdade formal e igualdade material é comumente usada a fim de elucidar o significado do princípio da isonomia. Brevemente, tem-se que a igualdade formal é apenas jurídica, tratando-se todos de forma igual, enquanto a igualdade material é real, ou seja, tratando-se as pessoas na proporção de suas desigualdades, o famoso postulado "tratar de forma desigual aqueles que se encontram em condições desiguais, na medida e proporção de suas desigualdades". Esta última é a igualdade almejada pelo princípio da isonomia. Segundo José Helvesley Alves, no passado tal desiderato não passava de uma ideologia, porém no presente configura realidade legal, expressa constitucionalmente:

Entretanto, o que antes permanecia apenas no campo ideológico, hoje faz-se presente no campo legal, mormente em mandamento constitucional, que deve ser cumprido para consecução de melhores condições de vida, cuja obrigatoriedade é do Estado para com o indivíduo que o forma e dele participa. É, portanto, dos governantes a tarefa de efetivar a determinação constitucional da igualdade material dos indivíduos. (ALVES, 2004, p. 154).

[...] a transformação da igualdade formal para a igualdade material, social, significando isso oportunidades para todos, só se alcança através da luta renhida, através das associações, dos sindicatos, das comunidades de base e outros meios existentes indispensáveis à consecução desse objetivo pelos menos aquinhoados.

É o que, em outras palavras, diz VON IHERING, verbis: "Todo direito que existe no mundo foi alcançado através da luta; seus postulados mais importantes tiveram de ser conquistados num combate contra as cortes dos opositores; todo e qualquer direito, seja o direito dum povo, seja o direito do indivíduo, só se afirma através duma disposição ininterrupta para a luta. O direito não é uma simples idéia, é uma força viva.... O direito representa um trabalho ininterrupto, não só do Poder Público, mas de toda a população. [...] (ALVES, 2004, p. 157).

O princípio da isonomia ou princípio da igualdade se encontra expresso na Constituição Federal Brasileira no artigo 5, caput: "Todos são iguais perante a lei, sem distinção de qualquer natureza, garantindo-se aos brasileiros e aos estrangeiros residentes no País a inviolabilidade do direito à vida, à liberdade, à igualdade, à segurança e à propriedade, 
nos termos seguintes". E, especificamente sobre a isonomia de gênero no inciso I do supracitado artigo: "homens e mulheres são iguais em direitos e obrigações, nos termos desta Constituição". Já na Lei Fundamental da Alemanha, encontra-se o princípio da isonomia expresso no artigo 3, que trata da igualdade perante a Lei, no número (1) observa-se a igualdade em termos gerais e nos itens (2) e (3) aborda-se a isonomia de gênero.

Além destes dispositivos, existem menções na Lei Maior dos dois países relativas aos servidores públicos e a isonomia relacionada ao gênero que deve nortear a atividade laboral. $\mathrm{Na}$ Constituição Federal do Brasil (artigos 37, 39 e $7^{\circ}$ ), encontram-se determinações quanto à obrigatoriedade de concurso público para investidura em cargo público, sendo este acessível a qualquer brasileiro ou estrangeiro que preencha os requisitos estabelecidos em lei, permitidos requisitos diferenciados de admissão quando a natureza do cargo o exigir. No entanto, ressalta-se que aos servidores ocupantes de cargo público é aplicável a proteção do mercado de trabalho da mulher, bem como a proibição de diferença de salários, de exercício de funções e de critério de admissão por motivo de sexo, idade, cor ou estado civil. Ademais, são garantidas licença maternidade e licença paternidade, apesar de só na primeira constar um número mínimo de dias. Na Lei Fundamental da Alemanha (artigo 33), por sua vez, expõe-se que todos os alemães têm os mesmos direitos e deveres cívicos, bem como têm igual acesso a qualquer cargo público, de acordo com sua aptidão, capacidade e desempenho profissional.

Sendo assim, observa-se que o princípio da isonomia se encontrava bem delineado nas legislações nacionais à época dos fatos expostos nas decisões judiciais supramencionadas. No caso julgado pelo Tribunal Constitucional Federal da Alemanha, sob a égide da Lei Fundamental de 23 de maio de 1949; e no caso julgado pelo Supremo Tribunal Federal do Brasil, sob a égide da Constituição Federal de 05 de outubro de 1988.

O princípio já era inclusive abordado na imposição de isonomia de gênero no serviço público, de forma a inibir as condutas verificadas nos casos analisados que, claramente, desprivilegiavam a família de servidora pública, deixando seu viúvo e filhos financeiramente desamparados quando do falecimento da esposa/mãe. Mais que isso, recolhendo da servidora pública do sexo feminino contribuição previdenciária de sua remuneração que, após sua morte, não seria destinada a fim algum, ao contrário do que ocorria com os servidores do sexo masculino cuja contribuição recolhida retornava em forma de pensão por morte a seus familiares. Porém, este é um assunto a ser destrinchado no próximo subitem do presente artigo, para o qual se segue. 


\subsection{Pensão por morte}

A prestação previdenciária de pensão por morte é um "benefício direcionado aos dependentes do segurado, visando à manutenção da família, no caso de morte do responsável pelo seu sustento. Este benefício será devido ao conjunto dos dependentes do segurado que falecer, aposentado ou não [...]" (IBRAHIM, p. 590). Verifica-se que a titularidade do benefício é dos dependentes e não do segurado, há uma variedade de beneficiários com direito a esta prestação, no entanto, no presente artigo o foco de estudo é apenas o cônjuge.

Inicialmente, observa-se a dificuldade em determinar a existência de dependência econômica ou de necessidade dos dependentes do segurado. Por isso, hoje em dia, no direito brasileiro a presunção de dependência econômica pertinente ao casal entre si, bem como dos filhos em relação aos pais é uma presunção absoluta, ou seja, quando solicitar o benefício o beneficiário não tem a necessidade de demonstrar a dependência (MARTINEZ, 2015, p. 492). Nas palavras de Fábio Ibrahim (2008, p. 591): “[...] De acordo com a Constituição, homens e mulheres são iguais em direitos e obrigações e, portanto, tanto um como outro fazem jus à pensão por morte deixada por seus respectivos parceiros, ainda que em união estável homossexual. Os filhos também são dependentes preferenciais [...]”.

Houve época, conforme mostrado no caso julgado pelo Tribunal Constitucional da Alemanha, na qual o cônjuge do sexo masculino tinha negado o seu direito à pensão por morte de sua esposa servidora pública por não poder ser considerado dependente desta. Devese expor aqui a inadequação de tal medida, tendo em vista que: $1^{\circ}$ ) o homem não é obrigado a trabalhar e ser a única ou principal fonte de renda de uma família, logo, a legislação deixava totalmente desprotegidas famílias que se organizavam fora do padrão tradicional, com a esposa trabalhando fora do domicílio e o marido trabalhando no lar ou com ambos trabalhando, porém sendo a maior renda proveniente da esposa; $2^{\circ}$ ) ignorava-se que em famílias nas quais marido e esposa trabalhavam fora do domicílio os rendimentos de ambos contribuíam para compor a renda familiar, portanto, a dependência econômica era mútua.

Também, no passado brasileiro, conforme revelado no caso julgado pelo Supremo Tribunal Federal o cônjuge do sexo masculino tinha negado o seu direito à pensão por morte de sua esposa servidora pública por não poder ser considerado dependente desta, exceto se fosse inválido. Neste ponto é importante ressaltar a injustiça de tal determinação, pois: $1^{\circ}$ ) a 
invalidez do viúvo precisava ser provada mediante perícia, enquanto a dependência econômica da viúva era absoluta, logo, impunham-se critérios diversos à percepção de pensão por morte de acordo com o gênero do beneficiário, bem como o critério para o recebimento do benefício pelo cônjuge do sexo masculino exigia prova, enquanto a viúva não precisava comprovar sua necessidade; $2^{\circ}$ ) o homem não é obrigado a trabalhar e ser a única ou principal fonte de renda de uma família, logo, a legislação deixava totalmente desprotegidas famílias que se organizavam fora do padrão tradicional, com a esposa trabalhando fora do domicílio e o marido trabalhando no lar ou com ambos trabalhando, porém sendo a maior renda proveniente da esposa; $3^{\circ}$ ) ignorava-se que em famílias nas quais ambos consortes trabalhavam fora do domicílio os rendimentos de ambos contribuíam para compor a renda familiar, portanto, a dependência econômica era mútua.

Verifica-se nas decisões analisadas que era dada a qualidade de beneficiários à viúva e aos filhos dos servidores públicos do sexo masculino, no entanto, tal não ocorria ao viúvo das servidoras públicas. Logo, o segurado servidor público tinha como dependentes sua esposa e seus filhos, enquanto a segurada servidora pública não tinha seu marido como dependente. Existiam dois segurados de gêneros distintos, ambos servidores públicos, ambos recolhendo contribuições previdenciárias, porém só o segurado do sexo masculino tinha o direito de resguardar seu cônjuge em caso de falecimento.

Aplicando-se o princípio da isonomia ao benefício da pensão por morte temos que nas mesmas condições, os beneficiários têm os mesmos direitos. Determinações que contrariem ao exposto estarão violando a igualdade e agindo de forma discriminatória, impondo um ônus injustificável a uma das partes. Nos casos analisados, verifica-se que esse ônus injustificável sendo aplicado tanto ao viúvo quanto à servidora pública. O primeiro porque foi tratado de forma discriminatória em razão de seu sexo, sendo privado de um direito que a viúva, beneficiária nas mesmas condições de fato que ele, podia usufruir. A segunda também foi tratada de forma discriminatória em razão de seu sexo, sendo privada de proteger a sua família por meio do benefício da pensão por morte, logo, a entidade familiar da servidora pública foi tratada pelo poder público como menos relevante, não merecendo a mesma proteção designada à família do homem servidor público.

O princípio da isonomia pode ser visto tanto como exigência de tratamento igualitário (Gleichbehandlungsgebot), quanto como proibição de tratamento discriminatório (Ungleichbehandlungsverbot). A lesão do 
princípio da isonomia oferece problemas sobretudo quando se tem a chamada exclusão de benefício incompatível com o princípio da igualdae (sic) (willkürlicher Begünstigungsausschluss). Tem-se uma exclusão de benefício incompatível com o princípio da igualdade se a norma afronta ao princípio da isonomia, concedendo vantagens ou benefícios a determinados segmentos ou grupos sem contemplar outros que se encontram em condições idênticas. Essa exclusão pode verificar-se de forma concludente ou explícita. Ela é concludente se a lei concede benefícios apenas a determinado grupo; a exclusão de benefícios é explícita se a lei geral que outorga determinados benefícios a certo grupo exclui sua aplicação a outros segmentos. (MENDES, 1994, p. 257).

Pode-se questionar: mas os filhos de servidora pública sempre foram beneficiários da pensão por morte, correto? Logo, ainda que o viúvo não fosse beneficiário da pensão por morte da servidora pública, a pensão por morte seria concedida aos seus filhos, de forma que a família não ficaria desamparada pelo empregador nesta circunstância. No entanto, deve-se lembrar que o benefício da pensão por morte era vitalício para as viúvas, enquanto para os filhos era apenas até estes completarem 21 anos, exceto se inválidos.

Desta forma, conforme as regras do benefício à época dos fatos narrados na decisão do Supremo Tribunal Federal, em casos nos quais o casal tivesse filhos, a pensão por morte da servidora não era paga ao seu viúvo e cessava para os filhos se não inválidos quando completassem 21 anos. Diferentemente do que acontecia na família de servidor público, na qual sua viúva recebia a pensão por morte vitaliciamente, assim, mesmo após cessar o pagamento para os filhos, as mães seguiam recebendo o benefício e proporcionando a toda entidade familiar melhores condições de vida por conta deste pagamento.

A razão de ser da previdência social é garantir o bem-estar e a segurança de seus segurados e seus dependentes, mas obviamente o legislador estadual não se lembrou disso quando redigiu as normas atinentes à pensão por morte de servidores públicos para o Estado de Minas Gerais, tampouco para o Estado de Renânia do Norte, em Vestfália. Se todos servidores públicos, sejam homens ou mulheres, estão sujeitos ao pagamento das contribuições, afronta-se o princípio da isonomia distinções entre os beneficiários viúvos e viúvas, privilegiando estas, eis que todos contribuem, conforme as mesmas regras, para financiar o sistema.

Finalizando os comentários relativos à negativa de dependência econômica do cônjuge sadio do sexo masculino, lembra-se que artigo 39 da Constituição Federal brasileira determina que o artigo $7^{\circ}$, inciso IV, do mesmo diploma legal, aplica-se aos servidores 
públicos. Logo, ao Estado cabe a proteção do servidor público e de sua família atendendo as suas necessidades vitais básicas. Frisa-se: marido e esposa formam família; e a família formada por servidor público e esposa, não é mais relevante do que a família formada por servidora pública e marido.

Recorrendo-se as normas nacionais e internacionais que tratam da proteção da família e da vida familiar, encontra-se em geral a formulação de noções abertas de família, que indicam a recepção dos mais diversos tipos familiares formados no seio social. Os diplomas refletem o abandono da unicidade de um modelo matrimonializado e patriarcal, que passa a dividir espaço com outras formas de constituição de família, desde que cumpridoras da sua função social, ética e espiritual. (CARVALHO, 2011, p. 67).

Analisando a exigência da legislação estadual mineira relativa à invalidez do viúvo para fins de recebimento de pensão por morte de servidora pública, conforme já exposto neste artigo, precisava ser provada mediante perícia médica, logo, exigia prova, lembrando que a viúva do servidor público não precisava provar sua dependência econômica, sendo a presunção desta absoluta. Além disso, ressalta-se que a invalidez do viúvo precisava existir na data do óbito da esposa servidora pública, a invalidez posterior não gerava direito ao benefício, pois era necessário preencher o critério de beneficiário à época do falecimento, bem como a incapacidade para o trabalho deveria ser insuscetível de reabilitação. Resta claro que o critério de invalidez aplicado apenas para o cônjuge do sexo masculino era profundamente prejudicial a este.

Ressalta-se que a isonomia tem por finalidade beneficiar aquele que se encontra em situação desfavorável, seu objeto não é prejudicar quem não se encontra nesta situação. Logo, regras cujo intuito seja a proteção da mulher, tendo em vista suas vulnerabilidades sociais, estão de acordo com o princípio da igualdade. No entanto, regras cujo objetivo seja prejudicar os homens, tendo em vista uma situação/condição social supostamente privilegiada em razão de seu gênero, violam o princípio supracitado. Tanto no caso alemão quanto no caso brasileiro, verificam-se regras prejudiciais, afinal, destas não decorrem quaisquer benefícios às viúvas de servidores públicos resultantes da oferta de proteção inferior aos viúvos de servidoras públicas.

10. Com efeito, por via do principio da igualdade, o que a ordem jurídica pretende firmar e a impossibilidade de desequiparações fortuitas ou 
injustificadas. Para atingir este bem, este valor absorvido pelo Direito, o sistema normativo concebeu formula hábil que interdita, o quanto possível, tais resultados, posto que, exigindo igualdade, assegura que os preceitos genéricos, os abstratos e atos concretos colham a todos sem especificações arbitrárias, assim proveitosas que detrimentosas para os atingidos. (MELLO, 2008, p. 18).

O principio da igualdade, nas suas várias dimensões, desempenha, também aqui, um papel importante na conformação do sistema, não se estranhando, pois, que se tenha recortado uma série de casos em que foi invocado. Repare-se que, para além dos casos de violação directa, importa não desconsiderar as hipóteses em que há uma violação indirecta, ou seja, em que estamos perante uma discriminação disfarçada. (LOUREIRO, 2008, p. 222).

Sendo assim, encerrada a análise comparativa da concessão de pensão por morte de servidora pública ao viúvo, com base em decisões do Tribunal Constitucional Federal da Alemanha e do Supremo Tribunal Federal do Brasil, sem abordar o atual regramento no Brasil e na Alemanha para fins de concessão do benefício, pois, conforme exposto na introdução, este não configura o objeto de análise no presente trabalho, estando o objeto aqui circunscrito à época das decisões judiciais abordadas. Segue-se para as considerações finais.

\section{CONSIDERAÇÕES FINAIS}

Ao longo deste artigo foram esmiuçadas duas decisões judiciais, uma do Tribunal Constitucional Federal da Alemanha e outra do Supremo Tribunal Federal do Brasil. Nestas, verificou-se que foi violado o princípio da isonomia, previsto em norma constitucional nos referidos países. Tal violação ocorre em prejuízo de servidora pública, bem como de viúvo desta.

A servidora pública era afetada na medida em que, apesar de igual em direitos e deveres aos servidores do sexo masculino, não usufruía da mesma proteção de sua entidade familiar. E, com respeito ao viúvo, pois a este era imposto critério para recebimento do benefício de pensão por morte mais rigoroso do que à viúva. Também, observou-se nos casos o preconceito em relação ao mercado de trabalho da mulher e a livre organização familiar, desprivilegiando casais não tradicionais para a época da legislação, nos quais a esposa está inserida no mercado de trabalho, podendo ser a provedora principal da família. 
O Judiciário em ambos os países reconheceu a violação ao princípio da isonomia e o direito do viúvo de receber o benefício de pensão por morte de sua esposa servidora pública. Assim, considerou nulas as legislações estaduais que impunham diferentes critérios para a percepção da prestação, sendo extremamente prejudicial para o viúvo e injustificável. Salientou-se que na Alemanha o critério a ser preenchido pelo viúvo a fim de fazer jus ao benefício era o da dependência econômica. Já na legislação estadual mineira o requisito era o da invalidez, no entanto, desta decorria a dependência econômica.

Buscando-se um conceito para o princípio da isonomia, concluiu-se que é aquele que oferece equiparação entre as partes, homogeneizando as relações e protegendo os que se encontram em situação de vulnerabilidade em um contexto específico. A isonomia não tem ideologias, bandeiras ou partidos para defender, a sua base é a defesa daquele que - quem quer que seja - está em situação de vulnerabilidade, igualando os desiguais e coibindo vantagens ou desvantagens injustificáveis. Assim, verificou-se que são possíveis ocorrências nas quais os homens estejam em situação de vulnerabilidade, sendo prejudicados em ofensa ao princípio da isonomia, conforme os casos estudados.

Sobre a pensão por morte, frisou-se que é um benefício direcionado aos dependentes do segurado, bem como que visa à manutenção da família, no caso de morte do responsável pelo seu sustento. Alertou-se sobre a injusta situação imposta pela lei, ou seja, a existência de dois segurados de gêneros distintos, ambos servidores públicos, ambos recolhendo contribuições previdenciárias, porém só o segurado do sexo masculino tendo o direito de resguardar seu cônjuge em caso de falecimento.

Também, destacou-se que o critério de invalidez na legislação mineira aplicado apenas para o viúvo era profundamente prejudicial a este. Além disso, ressaltou-se que aplicando o princípio da isonomia ao benefício de pensão por morte temos que nas mesmas condições, os beneficiários têm os mesmos direitos. Logo, determinações que contrariem o exposto estarão violando a igualdade e agindo de forma discriminatória, impondo um ônus injustificável a uma das partes.

Portanto, reafirma-se a semelhança entre os casos esmiuçados. Estes mostram o preconceito de gênero que há poucas décadas impregnava a legislação dos países analisados, bem como ressaltam o papel fundamental desempenhado pelas Cortes superiores de ambos os países em reparar injustiças na legislação infraconstitucional e a importância da Lei Maior. 


\section{REFERÊNCIAS}

ALEMANHA. Lei Fundamental da República Federal da Alemanha: promulgada em 23 de maio de 1949. Disponível na URL: https://www.btg-bestellservice.de/pdf/80208000.pdf. Acesso em 26 de maio de 2019.

ALVES, José Helvesley. Isonomia constitucional. Igualdade formal versus igualdade material. Disponível na URL: https://www.jfpe.jus.br/images/stories/docs_pdf/biblioteca/ artigos_periodicos/JoseHelvesley_Alves/ isonomia_revESMAFE_n7_2004.pdf. Acesso em 30 de maio de 2019.

BRASIL. Constituição (1988). Constituição da República Federativa do Brasil: promulgada em 5 de outubro de 1988. Disponível na URL: http://www.planalto.gov.br/ccivil_03/ constituicao/constituicao.htm. Acesso em 26 de maio de 2019.

CARVALHO, Carla Vasconcelos. Família Unipessoal. Revista da Faculdade de Direito da Universidade Federal de Minas Gerais, 59, 2011, pp. 57-78. HeinOnline.

D'OLIVEIRA, Maria Christina Barreiros. Breve análise do princípio da isonomia. Disponível na URL: http://institutoprocessus.com.br/2012/wp-content/uploads/2011/12/3 _edicao1.pdf. Acesso em 26 de maio de 2019.

LOUREIRO, Joao Carlos. Constituição da Segurança Social: Sujeitos, Prestações e Princípios. Boletim da Faculdade de Direito da Universidade de Coimbra, 84, 2008, pp. 189250. HeinOnline.

MELlO, Celso Antônio Bandeira de. Conteúdo Jurídico do Princípio da Igualdade. 3. ed. São Paulo: Malheiros, 2008.

MENDES, Gilmar Ferreira. A doutrina constitucional e o controle de constitucionalidade como garantia da cidadania - necessidade de desenvolvimento de novas técnicas de decisão: possibilidade da declaração de inconstitucionalidade sem a pronúncia de nulidade no direito brasileiro. Revista da Faculdade de Direito da Universidade Federal de Minas Gerais, 34, 1994, pp. 241-274. HeinOnline.

IBRAHIM, Fábio Zambitte. Curso de Direito Previdenciário. 12. ed. Rio de Janeiro: Impetus, 2008.

MARTINEZ, Wladimir Novaes. Princípios de Direito Previdenciário. 6. ed. São Paulo: LTr, 2015.

TRIBUNAL CONSTITUCIONAL FEDERAL. BVerfGE 39, 196. Disponível na URL: http://www.servat.unibe.ch/dfr/bv039196.html. Acesso em 26 de maio de 2019.

SCHWABE, Jürgen. Cinqüenta anos de jurisprudência do Tribunal Constitucional Federal Alemão. Montevideo: Konrad-Adenauer-Stiftung, 2005. 
STF. Agravo Regimental no Recurso Extraordinário: RE 385397 AgR/MG. Relator: Ministro Sepúlveda Pertence. D.J.: 06.09.2007. Disponível na URL: http://redir.stf.jus.br/paginadorpub /paginador.jsp?docTP=AC\&docID=485500. Acesso em 26 de maio de 2019. 